\title{
Sport Diplomacy: Sport's Impact as a Form of Soft Power on Peacebuilding and Nation-Building in the Israeli-Palestinian Conflict
}

By Ender McDuff

Author Note I would like to thank Majka Hahn, my POLI 347 TA, for inspiring me to explore the topic of sport diplomacy in relation to the Israeli-

Palestinian conflict. As a lifelong lover of sports, researching and writing this

paper afforded me a rare opportunity to combine my academic interests with

gthletics, all while exploring the incredibly important topic of peacebuilding.

My further thanks go to Professor Daniel Douek for the excellent

education he provided to me and every student in POLI 347. His

siogtful lectures and even-handed approach to the material make the

celass one of McGill's best. Lastly, I would like to thank my editors,

Asher Laws and Alicia Wilson, for all their help and guidance. Their

insight and suggestions greatly benefitted my paper.

was a great delight to write "Sport Diplomacy" and I hope all enjoy

Abstract Since the founding of the first Israeli and Palestinian soccer clubs in 1906 and 1908, respectively, sport has played an intimate role in the Israeli-Palestinian conflict. Whether as a training ground for counter-insurgency operations or an extension of the nation's foreign policy apparatus, sport has been utilized by both parties as a tool for peacebuilding and nation-building. The purpose of this article is to examine whether sport, through what is termed sport diplomacy, can help establish the conditions necessary for successful peace negotiations in the IsraeliPalestinian conflict. To this effect, the paper adopts the analytical lens of sport as a form of soft power. Following this framework, the paper considers how sport diplomacy operates as a tool for image-building, constructing a platform for dialogue, trust building, and as a catalyst for reconciliation in the context of the Israeli-Palestinian conflict. The article concludes that sport can indeed help establish the conditions needed for successful peace negotiations; however, sport should not yet be employed as a path to reconciliation until such time as a political peace is firmly established.

This article was submitted to POLI 347: Arab-Israel Conflict, Crisis, Peace

Edited by Asher Laws and Alicia Wilson

Flux: International Relations Review, Volume X 
McDuff 54

\section{Introduction}

The conflict in modern day Israel and the occupied territories of Palestine - the West Bank and Gaza - has an intimate association with sport that dates back to the foundation of the first Israeli and Palestinian soccer clubs in 1906 and 1908, respectively (Xenakis and Lekakis 2018, 334). While George Orwell once described sports as "war minus the shooting," this observation may have journeyed a step too far in the context of the Israeli-Palestinian conflict (Orwell 1950). At various times throughout the conflict's history, sport has acted as a catalyst for so-called muscular Jewish identity, as a training ground for both Israeli militias and Palestinian youth preceding the 1948 Arab-Israeli War and the First Intifada, and, most recently, as a highly politicized arena in which each actor's respective football league - the Israeli Football Association (IFA) and the Palestinian Football Association (PFA) - is acting in coordination with the nation's foreign policy interests (Schleifer and Tamir 2018, 50, 52; Xenakis and Lekakis 2018, 346). In this manner, sport has been integral to a conflict in which, as of yet, peace remains elusive. Even so, what role might sport play in an eventual process of peacebuilding and future reconciliation?

By examining select historical events in which sport played a critical role through the lens of soft power, this paper argues that sport can help establish the conditions necessary for successful peace negotiations through the mechanisms of image-building, trust-building, and constructing a platform for dialogue. The paper finds, however, that sport cannot bring about meaningful reconciliation until a prior political peace is established. This will be illustrated by presenting soft power as an analytical framework through which to explain the role of sport in political conflicts and peacebuilding, then by analyzing the role of sport in the Israeli-Palestinian conflict pursuant to this framework. First, sport will be considered and critiqued as a means for image-building and, thereby, nation-building. Next, the role of sport in building a platform for dialogue and trust will be explored and these conditions will be compared to those situations present in the successful 1978 Camp David Accords and the 1993/95 Oslo Accords. Lastly, sport as a tool for reconciliation, integration, and the promotion of anti-racism will be examined and a critique of such practices, at this stage in the conflict, will be levied. In so doing, this paper concludes that sport serves as an effective means of soft power that can help establish the conditions necessary for successful peace negotiations, but that it should not be employed as a path to reconciliation until political peace is firmly established.

\section{Analytical Framework: Soft Power and Sport}

To understand the role sport has played in the Israeli-Palestinian conflict, this paper uses an analytical framework based on the concept of soft power and its relation to peacebuilding and nation-building. First proposed in 1990 by neoliberal theorist Joseph Nye, soft power refers to "the ability to affect others to obtain what one wants through attraction" or, more simply put, to get another to want what you want (Rugh 2009, 4). This notion adds a second constitutive piece to the traditional notion of hard power which previously referred exclusively to the ability of an actor to influence others through either coercive threats or inductive payments.

Recent literature on the subject has begun to critically study how sport is used as a form of soft power through what is termed sport-diplomacy. Michael Barnett and Raymond Duval identify institutional and representational power as two specific types of soft power pertinent to sportdiplomacy $(2005,43)$. The former considers how "institutions that mediate between actors" including traditionally non-partisan bodies like the Fédération Internationale de Football Association (FIFA) - can be leveraged to control other actors. The latter articulates the statusseeking behaviour of actors as a means of "enjoy[ing] a high representation in the international community [which permits them] to coerce other actor[s]" (Xenakis and Lekakis 2018, 331). In instances of peace negotiations specifically, sport also offers a venue through which actors can

Flux: International Relations Review, Volume $X$ 
engage in the politics of persuasion, a critical component of any negotiation process (Nygård and Gates 2013, 237). Håvard Mokleiv Nygård and Scott Gates identify four key mechanisms through which sport diplomacy can help facilitate such outcomes: image-building, building a platform for dialogue, trust-building, and reconciliation (2013, 237).

\section{Image-Building}

The first mechanism of sport-diplomacy is image-building. This strategy traditionally involves an economic investment to host a major sporting event, like the Olympics or the FIFA World Cup, as a means of establishing political capital (Nygård and Gates 2013, 238). Hosting such an event acts as a form of public diplomacy - "a deliberate act designed to communicate with [a] foreign public" to amplify soft power and prestige-by signaling the state's arrival on the world stage and bestowing upon that state the world's undivided attention (Nygård and Gates 2013, 238; Rugh 2009, 14). Recent work by Patrick Rhamey and Bryan Early demonstrates, however, that image-building is not only reserved for an event's host, as doing well in the competition or even simply being present can enhance international prestige $(2013,245)$. This is because, at its core, image-building is an appeal to nationalism-an ideology intimately tied to the IsraeliPalestinian conflict. Nationalism, according to an ethno-symbolic approach, is largely a modern phenomenon because a nation's foundation rests on a culture that is (re)constructed by the interaction of its members with one another as a distinct, imagined community (Xenakis and Lekakis 2018, 329). Ethno-symbolism acknowledges, however, that such nationalism contains premodern roots, as "nations reach back to the myths, memories, and symbols of a pre-modern era in order to (re)construct the nation" (330). The historical Israeli-Palestinian conflict is predominantly a result of competing Arab and Jewish nationalisms in the late nineteenth and early twentieth centuries. Both movements were founded on ethnic nationalism: Zionism first as a "quest... for the creation of a Jewish state [in Palestine]" and Palestinian nationalism following as an "intimately intertwined" result (Caplan 2010, 4; Khalidi 1998, 146). As such, both movements believe that "their existences require a geographical reference point" located in the modern-day territory of Israel and Palestine (Xenakis and Lekakis 2018, 334).

Sport is intrinsically connected to such attempts at nation-building, as "sport constitutes a charged [ritual of] interaction... out of which imagined national communities arise" (Xenakis and Lekakis 2018, 331). As such, sporting events can provide recognition to national communities and can foster political socialization amongst fans and athletes alike (332). The overt national symbols present at sporting events further emphasize the reconstruction of the nation and "serve as a substitute for the unifying frameworks that modernity has eroded" (Schleifer and Tamir 2018, 46). The context of nationalism in the Israeli-Palestinian conflict is somewhat unique, however, in that rather than involving nationalism between nation-states, it involves an asymmetric nationalism involving "submerged" nations. The first of which is the Zionist nation of Israel within British Mandate Palestine and the second is the Palestinian nation, distinct from the sovereign state of Israel, in Gaza, the West Bank, refugee camps in neighbouring countries, and in the larger global Palestinian diaspora (Xenakis and Lekakis 2018, 332; Dart 2019, 4). In this case then, both Israeli and Palestinian nationalism have "use[d] sporting events as opportunities to stimulate selfawareness and political mobilization... [which]... push[es] toward the creation of a nation-state" (Xenakis and Lekakis 2018, 332).

For both Israel and Palestine, nationalism and sport have been connected through forms of image-building as each party aims to be included as a member of and hold relative standing in defined clubs that signify the legitimacy of their nationalist claims (Nygård and Gates 2013, 238). The first historical occurrence of such image-building took place in 1929, when Russian-born Jew and football enthusiast Josef Yekutieli founded the forerunner to the IFA and secured its

Flux: International Relations Review, Volume X 
membership in FIFA (Schleifer and Tamir 2018, 335). While such membership theoretically mandated that the league maintain equal representation of all races and religions, the IFA "de facto comprised mainly Jews" (Xenakis and Lekakis 2018, 51). The Zionist movement would also go on to represent the Mandate territory at the 1936 Olympic Games (Schleifer and Tamir 2018, 51). Following Israeli independence after the 1948 Arab-Israeli War, Israel sought to further establish its legitimacy by applying to the International Olympic Committee in 1952 and both the Asian Football Confederation and the Asian Games in 1954. These actions constituted the exact statusseeking behaviour predicted by representational power and serves to bolster Israel's image as well $(51,53)$.

Palestinians have likewise since pursued an image-building strategy. Nygård and Gates note that sporting events "present an opportunity for third-party political actors to further their own cause". This form of image-building was used by the Palestinian terrorist group Black September when they kidnapped and ultimately killed 11 Israeli athletes during the 1972 Olympic Games to "maximize the symbolism of [the Palestinian] cause". (2013, 238) Following the first Oslo Accords in 1993, the PFA has adopted the representational power model utilized by Israel, applying to the International Olympic Committee in 1994 and FIFA in 1998 (Schleifer and Tamir 2018, 53).

Palestine and other Arab states have also sought to counter the image-building efforts of Israel. One method is with boycotts, which is widely supported by the Boycott, Divestment, Sanctions (BDS) movement. This was exemplified at the 2007 Youth Olympic Games when Israeli Gili Haimovitz won gold because his competitor abstained from the match (Nygård and Gates 2013, 238; Schleifer and Tamir 2018, 53). Most consequentially, however, the PFA also sought to remove Israel from FIFA in April 2015 for its "occupation policy and discrimination against Palestinians... [which] hinder[s]... the development of Palestinian athletics" (Schleifer and Tamir 2018, 54). This agenda allowed the PFA to internationalize the conflict, delegitimize Israel by labelling it an Apartheid state, and increase the standing of the Palestinian national team (55). While the United States - for unclear reasons, according to Demetrios Xenakis and Nikos Lekakis - intervened two days before the decisive vote by announcing indictments against FIFA, the PFA was still able to widely publicize Israel's wrongdoings and extract key concessions that allowed the first football game in 15 years between a West Bank team and a Gaza team on August 4, 2015. These results also leave open the possibility for the future suspension of Israel's football membership. (Xenakis and Lekakis 2018, 345) This episode demonstrated Israel's unwillingness to recognize the PFA for fear that "it [would] signal the [PFA's] symbolic representation of a Palestinian nation-state [and] not an enclave within Israel," which shows how institutional and image-building soft power "has emerged as a potent weapon for the Palestinians" (Xenakis and Lekakis 2018, 346).

There is, however, a substantive critique of the image-building mechanism. While sporting events can be used as a means of building trust and peace between adversaries, there may be unintended consequences too, as hostilities between peoples can be mirrored in the game. Nationalist tensions can be exacerbated when sports become "jingoistic [and] create tension... rather than understanding". (Nygård and Gates 2013, 240) Research by Raul Caruso and Marco Di Domizio suggests further that sport, rather than building trust, tends to reflect the larger political environment within which it is occurring $(2013,13)$. Meanwhile, nationalism in sports has contributed to the creation of ethnic hierarchies and other forms of division (Xenakis and Lekakis 2018, 240). While these concerns are valuable to understand, they should not on their own preclude the use of sport-diplomacy as a means of image-building and peacebuilding. In a conflict as fervent as that in Israel-Palestine, any option poses the risk of heightened nationalist

Flux: International Relations Review, Volume $X$ 
sentiments. The proven successes thus far, however, indicate how image-building as a form of public diplomacy, with the added support of representational and institutional power, can help actors establish themselves as nation-states within the international community. This was successfully completed by the Israeli nation in forming the state of Israel and is currently being used by the Palestinian nation in an effort to construct their own state.

\section{Building a Platform for Dialogue and Trust-Building}

The next two mechanisms, building a platform for dialogue and trust-building, are related as they both directly establish the conditions necessary for peace negotiations. With respect to the former, sporting events "strengthen ties between nations... and provide a venue for peaceful cultural exchange, which can serve as the basis for the further normalization of political relations" (Nygård and Gates 2013, 239). With respect to the latter, sport can also foster trust-building between communities and their leaders. This is engendered through the personal interactions that occur on and off the field during sporting events, through which understandings and friendships can develop. Essentially, peace can be a bottom-up development established through the interaction of individuals. In this sense, efforts to build a platform for dialogue and trust building encourage relationship building between states, whereas image-building-as discussed prior-was concerned with a state's self-promotion over another state. (239) Nevertheless, these two mechanisms do pose the threat of harming relationships, should athletes or fans act in a manner that is hostile to one another.

It is also advantageous to examine how these two conditions relate to the broader literature on successful Arab-Israeli and Israeli-Palestinian peace negotiations. This is pertinent to explore because several of the components that academics have highlighted as integral to traditional diplomatic efforts are also mirrored in sport-diplomacy through the mechanisms of building a platform for dialogue and trust-building. Reflecting on the 1978 Camp David Accords between Israel and Egypt, Janice Gross Stein argues that the expansion of each leader's domestic win-sets - the outcomes acceptable to a state's public - were critical to the negotiation's success. Such an expansion was achieved through public diplomacy, which appealed to public opinion in the foreign country. This provided a moment of connection between communities and their leaders that "created...psychological and political symbols [that] would mobilize public opinion" and could not be undone (1993, 86). Additionally, reflecting on the 1993 and 1995 Oslo Accords, President Bill Clinton emphasized the importance of trust between Israeli Prime Minister Yitzhak Rabin and Palestine Liberation Organization Chairman Yasser Arafat in engendering peace (TOI Staff 2015). These two conditions, which are necessary for successful peace negotiations, can be facilitated by sport because sporting events - like Egyptian President Anwar Sadat's speech to the Israeli Knesset prior to the 1978 Camp David Accords - are permanent, offer powerful symbolism, and provide a platform for leaders to connect. In addition, sport fosters trust amongst the public and between leaders, as was so critical to the Oslo Accords. In these ways, sport-diplomacy recreates the same conditions that have already proven effective in prior diplomatic efforts. This suggests that sport does indeed constitute an effective means of soft power for establishing the conditions necessary for peace negotiations.

This connection between sport-diplomacy and traditional diplomacy may, in the case of the Israeli-Palestinian conflict, even go a step further: historic sporting events notably occurred before or at the same time as the aforementioned peace negotiations. It must be acknowledged, however, that while the following connections demonstrate strong circumstantial evidence, the analysis is limited as available literature is insufficient for drawing direct causal links. In 1976, two years before Camp David, Rifaat Turk and Ali Othman made history as the first Arab players to join the Israeli national soccer team (Schleifer and Tamir 2018, 49). This development created the

Flux: International Relations Review, Volume X 
possibility of a "joint symbol for both the Jewish and the Arab citizens of [Israel]," which eventually led to the Israeli soccer team becoming a national symbol for Jewish and Arab Israelis alike. This development may well have helped build trust and the conditions necessary for the subsequent dialogue between Israel and their main Arab adversary, Egypt. (49) Subsequently, the 1995 Norway Cup - an international youth football tournament - was the first time since state formation that a Palestinian team played an Israeli team. This was such an important event that when the Palestinian team traveled to Oslo, Yasser Arafat momentarily left the peace talks to go to the airport to wish the team good luck. (Nygård and Gates 2013, 239) This situation initially offers an instance of reverse causality, as it is likely that the ongoing peace negotiations in Oslo were responsible for establishing the trust necessary for the game to occur in the very same city. It is difficult to deny, however, that the successful completion of the Israeli-Palestinian game contributed in turn to furthering the trust between Israeli and Palestinian peoples and negotiators, as was critical to the successful Oslo II Accord signed later that year. In this respect, sport diplomacy and traditional diplomacy can be viewed as mutually reinforcing activities. This would suggest that while sport alone cannot establish a political peace, it does indeed offer a mechanism for building a platform for dialogue and trust-building, as seen in each of these cases, respectively.

\section{Catalyst for Reconciliation, Integration, and the Promotion of Anti-Racism}

Lastly, sport can operate as a catalyst for reconciliation, integration, and the promotion of anti-racism (Nygård and Gates 2013, 240). Reconciliation is a component of peacebuilding that focuses on establishing a genuine moral and psychological change in attitudes between parties after a conflict. To quote Jon Dart, a Senior Lecturer in Sports Policy and Sociology, "peacebuilding involves not only the ending of violence but also a transformation in the relationship among those affected" (Dart 2019, 6). Most sport-based reconciliation efforts build off the success of the 1995 Rugby World Cup, which was held in South Africa only a year after President Nelson Mandela was elected in the country's first elections since the disestablishment of Apartheid (Steenveld and Strelitz 1998, 9). Rugby, once a symbol of Apartheid, allowed Mandela to "promote a vision of South Africanism [that] transcended the primordial view of ethnic identity promoted by Apartheid ideology" and united all behind the South African rugby team (609). While Israel has not been granted the opportunity to host such an event, there are still 13 micro-level attempts to engender reconciliation through sport (Dart 2019, 7). These so-called sport-for-peace initiatives purport to establish a bottom-up approach to reconciliation that build peace and resolve conflict within communities (Dart 2019, 7).

Dart levies a harsh critique, however, against the premature use of such reconciliation processes in the Israeli-Palestinian conflict. The sport-for-peace approach is not, according to Dart, "an appropriate vehicle for peacebuilding between Israelis and Palestinians because there is no peace - a necessary precursor for reconciliation" $(2019,1)$. As the most contemporary author cited in this paper, Dart's argument is informed by the Palestinian people's ongoing struggle for human rights due to the West Bank barrier and the expansion of Israeli settlements into the West Bank. Dart concludes that these actions by the Israeli government make ever more unlikely a possible two-state solution. (5) On this basis, Dart asserts that reconciliation initiatives undermine "the principles of passive resistance to the occupation" and legitimize a situation wherein Israel continues ever closer to absorbing the West Bank $(8,18)$. This asymmetric relationship is made evident by considering that the exchange goes entirely in one direction, as there are no Palestinian-led sport initiatives seeking to build bridges with Israelis (18). Given this critique, it is important to assert that the time for reconciliation initiatives in the Israeli-Palestinian conflict have not yet come. The actions of the current Israeli government under Prime Minister Benjamin Netanyahu to increase settlements considered illegal by international law precludes sport from

Flux: International Relations Review, Volume $X$ 
effectively encouraging reconciliation (Kershner 2019). Instead, sport-for-peace initiatives at the micro-level threaten to legitimize a status-quo wherein there is no two-state peace agreement. As such, sport as a tool for reconciliation is best reserved for use until a lasting political peace can first be established.

\section{Conclusion}

Both sides in the Israeli-Palestinian conflict have utilized and continue to employ sport as an "essential instrument in their nation-building efforts," and it is near doubtless that this trend will continue (Xenakis and Lekakis 2018, 337). Yet, as Israel expands settlements in the West Bank, the two sides seem further away from peace day by day. For those still driven by the pursuit of a two-state solution, however, sport may still provide a valuable soft power tool for peacebuilding.

This paper began by arguing that sport can be and has been used effectively as an imagebuilding tool. When paired with the soft power structures of institutional and relational power along with public diplomacy, sport was valuable in allowing the Israeli state to gain a place within the international community. While Palestine has not yet been entirely successful in this endeavour, the PFA's effort to remove the IFA from FIFA amply demonstrates the potential for the PFA to further build its image through sport. These two presentations of image-building also serve to discount the risk that sport, as an unpredictable medium, may further heighten nationalistic tensions. Next, this paper established the role of sport in building a platform for dialogue and trust-building, and how these two elements both replicate the conditions of successful peace negotiations and correlate with such successes. Based on these three mechanisms, this paper confidently concludes that sport, as a form of soft power, has a valuable role to play in establishing the conditions necessary for successful peace negotiations. With this said, the current Israeli sport-for-peace initiatives constitute a premature act of reconciliation that only serves to legitimize a status-quo that is trending away from a two-state peace agreement. Therefore, sport as reconciliation may ultimately harm the peace process and should be reserved for after a lasting political peace is established. In this sense, while sport diplomacy and traditional diplomacy may play a mutually reinforcing role in building relationships and, eventually, a lasting peace, this peace may not be attainable for a considerable amount of time.

Flux: International Relations Review, Volume X 


\section{References}

Barnett, Michael and Raymond Duvall. 2005. "Power in International Politics." International Organization 59, no. 1: 39-75. DOI: https://doi.org/10.1017/S0020818305050010

Caplan, Neil. 2010. The Israel-Palestine Conflict. West Sussex: Wiley-Blackwell Publishing. https://www.wiley.com/en$\mathrm{ca} /$ The+|srael+Palestine+Conflict\%3A+Contested+Histories\%2C+2nd+Edition-p9781119523871.

Caruso, Raul and Marco Di Domizio. 2013. "International hostility and aggressiveness on the soccer pitch: Evidence from European Championships and World Cups for the period 2000-2012." International Area Studies Review 16, no. 3: 262-273. DOI: $10.1177 / 2233865913499267$.

Dart, Jon. 2019. "Sport and Peacebuilding in Israel/Palestine." Journal of Global Sports Management. DOl: 10.1080/24704067.2019.1604073.

Kershner, Isabel. "Are West Bank Settlements Illegal? Who Decides?" The New York Times. November 18, 2019. https://www.nytimes.com/2019/11/18/world/middleeast/israelwest-bank-settlements.html.

Khalidi, Rashid. 1998. Palestinian Identity. New York: Columbia Press.

Nygård, Håvard Mokleiv and Scott Gates. 2013. "Soft power at home and abroad: Sport diplomacy, politics and peace-building." International Area Studies Review 16, no. 3: 235 243. DOl: 10.1177/2233865913502971.

Orwell, George. 1950. The Sporting Spirit. London: Secker and Warburg.

Rhamey, Patrick J. and Bryan R. Early. 2013. "Going for the gold. Status-seeking behavior and Olympic performance." International Area Studies Review 16, no. 3: 244-261. DOl: 10.1177/2233865913499563.

Rugh, William A. 2009. "The Case for Soft Power." In Toward a New Public Diplomacy, edited by P. Seib. New York: Palgrave Macmillan, 3-21.

Schleifer, Ron and Ilan Tamir. 2018. "The use of sport in the Arab-Israeli conflict." Israel Affairs 24, no. 1: 45-61. DOl: 10.1080/13537121.2017.1398466.

Steenveld, Lynette and Larry Strelitz. 1998. "The 1995 Rugby World Cup and the politics of nation building in South Africa." Media, Culture \& Society 20, no. 4: 609-629. DOl: 10.1177/016344398020004006.

Stein, Janice Gross. 1993 "The Political Economy of Security Arrangements: The Linked Costs of Failure at Camp David." In Double-Edged Diplomacy: International Bargaining and Domestic Politics, edited by P. Evans, H. Jacobson and R. Putnam. Berkley: University of California Press, 77-103.

Flux: International Relations Review, Volume X 
Times of Israel Staff. "Clinton: I really loved Rabin, and he would have reached a final peace deal." Times of Israel. October 27, 2015. https://www.timesofisrael.com/clinton-i-really-lovedrabin-and-he-would-have-made-peace/.

Xenakis, Demetrios and Nikos Lekakis. 2018. "From Hasbara to the Palestine-Israel Sport Conflict." Diplomacy \& Statecraft 29, no. 2: 328-351. DOl:10.1080/09592296.2018.1453984.

Flux: International Relations Review, Volume X 